\title{
Peramalan Jumlah Penumpang Pada Siluet Tour And Travel Kota Malang Menggunakan Metode Triple Exponential Smoothing
}

\author{
Vivi Aida Fitria ${ }^{1}$, Rudi Hartono ${ }^{2}$ \\ STMIK Asia Malang \\ 1viviaidafitria@gmail.com, ${ }^{2}$ ruddiblue27@gmail.com
}

\begin{abstract}
ABSTRAK. Pada penelitian ini dilakukan peramalan jumlah penumpang pada Siluet Tour and Travel, yaitu salah satu perusahaan yang bergerak dalam bidang jasa tour dan travel. Karena data jumlah penumpang mengandung unsur musiman, peramalan pada penelitian ini menggunakan metode Triple Exponential Smoothing. Tahapan yang dilakukan pada proses peramalan meliputi input data, uji data, proses perhitungan, dan output. Hasil dari pengolahan dataset digunakan untuk perhitungan proses ramalan yang menghasilkan MAPE $=9,86$ alpha $=0,4 \mathrm{~m}=1$ dengan hasil peramalan jumlah penumpang pada bulan November 2015 adalah 501. Hasi peramalan jumlah penumpang tersebut diimplementasikan dalam sebuah aplikasi peramalan.
\end{abstract}

Kata Kunci : Triple Exponential Smoothing, Peramalan, Jumlah Penumpang

\section{PENDAHULUAN}

Peranan jasa tour and travel saat ini sangat berpengaruh pada masyarakat. Karena sangat membantu dalam hal berpergian ataupun berwisata. Akan tetapi terdapat beberapa kendala dalam berwirausaha dibidang jasa tour and travel salah satunya adalah jumlah penumpang. Karena dalam satu waktu terkadang para penumpang bisa naik ataupun turun tanpa bisa diprediksi. Agar tidak terjadi sesuatu yang dapat merugikan para pelaku wirausaha bisa mengantisipasi dengan cara meramalkan jumlah penumpang. Sehingga dari pihak pelaku wirausaha di bidang jasa tour and travel dapat membuat beberapa strategi untuk mengantisipasi jika terjadi penurunan jumlah penumpang misalkan dengan menambah iklan, rute tujuan kota, paket wisata, dan mempersiapkan kendaraan serta driver ataupun pelayanan agar dapat memuaskan penumpang.

Sehingga meramalkan jumlah penumpang sangat diperlukan untuk mencegah hal yang dapat merugikan pada perusahaan jasa tour and travel. Peramalan merupakan alat bantu yang penting dalam perencanaan yang efektif dan efisien (Makridakis dkk, 1999). Peramalan adalah apa yang akan terjadi pada waktu yang akan datang, sedang rencana merupakan penentuan apa yang akan dilakukan pada waktu yang akan datang (Subagyo, 1986). Salah satu metode dalam peramalan adalah Metode Exponential Smoothing dibagi menjadi tiga kelas Exponential Smothing sesuai dengan pola data time series, meliputi metode Single Exponential Smoothing untuk pola data yang bersifat horisontal, metode Double Exponential Smoothing untuk data yang mengalami trend, dan metode Triple Exponential Smoothing untuk data trend dan terdapat pengaruh musiman (Firmansyah, 2010).

Peramalan menggunakan Metode Exponential Smoothing sudah sering dipakai peneliti salah satunya diterapkan pada Sistem Informasi Pengendalian Produk dan Bahan Baku. Hasil uji coba menunjukkan bahwa nilai persentase peramalan terhadap data aktual kurang dari $10 \%$ yang berarti nilai ramal memiliki ketepatan yang cukup tinggi. Pengaruh parameter pada metode Exponential Smoothing, yaitu untuk memuluskan data dengan menghilangkan pengaruh random, trend, dan musiman pada data. Tiap bahan baku memiliki nilai parameter yang berbeda-beda untuk menghasilkan nilai MAPE terkecil. Dari hasil uji coba didapatkan bahwa setiap bahan baku memiliki karakteristik data time series yang berbeda sehingga masing-masing produk parameter ramalan berbeda dengan produk lainnya (Pramita,2010). Berdasarkan uraian diatas, maka dirancang aplikasi untuk peramalan penumpang Siluet tour and travel dengan judul "Peramalan Jumlah Penumpang Pada Siluet Tour and Travel Kota Malang Menggunakan Metode Triple Exponential Smoothing”.

\section{KAJIAN TEORI}

\subsection{Peramalan}

Peramalan berasal dari kata ramalan yang artinya adalah suatu situasi atau kondisi yang diperkirakan akan terjadi pada masa yang akan datang. Sedangkan peramalan adalah bentuk kegiatannya. Ramalan tersebut dapat didasarkan atas bermacam-macam cara yaitu metode single exponential smoothing, metode double exponential smoothing, metode triple exponential smoothing. Semua itu dikenal dengan metode peramalan. Peramalan adalah memperkirakan keadaan dimasa yang akan datang melalui pengujian keadaan dimasa lalu. Dalam kehidupan sosial segala sesuatu itu serba tidak pasti, sukar 
diperkirakan secara tepat. Dalam hal ini diperlukan peramalan. Peramalan yang dibuat selalu diupayakan agar dapat meminimumkan pengaruh ketidakpastian ini terhadap sebuah masalah. Dengan kata lain peramalan bertujuan mendapatkan peramalan yang bisa meminimumkan kesalahan meramal (forecast error) yang biasanya diukur dengan mean square error, mean absolute error, dan sebagainya (Makridakis,1999).

\subsection{Koefisien Autokorelasi}

$\mathrm{rk}=$ koefisien autokorelasi untuk $\mathrm{k}$ dari lag

$$
r_{S}=\frac{\sum_{i=2+1}^{\mathrm{n}}\left(Y_{2}-\bar{Y}\right)\left(Y_{i k}-\bar{Y}\right)}{\sum_{i=1}^{n}\left(Y_{2}-\bar{Y}\right)^{2}} \quad k=0,1,2, \ldots
$$

$\bar{Y}=$ mean dari data observasi

$\mathrm{Yt}_{\mathrm{t}}=$ observasi pada periode waktu $\mathrm{t}$

Yt-k = observasi $\mathrm{k}$ periode waktu sebelumnya atau periode waktu $\mathrm{t}-\mathrm{k}$

\subsection{Exponential Smoothing}

Smoothing adalah mengambil rata- rata dari nilai pada beberapa periode untuk menaksir pada suatu periode. Exponential Smoothing adalah suatu metode peramalan rata- rata bergerak yang melakukan pembobotan secara menurun secara exponential terhadap nilai observasi yang lebih tua. Bobot yang diberikan tersebut berciri menurun secara exponensial dari titik data terakhir sampai data yang terawal. Jika dalam perhitungan peramalaan diamsusikan nilai mean nya konstan sepanjang waktu, maka akan diberikan bobot yang sama terhadap setiap observasi. Oleh karena itu diberikan bobot yang lebih pada nilai observasi yang baru dan mengurangi bobot pada observasi yang lebih lama.

\subsection{Triple Exponential Smoothing}

Rumus yang digunakan untuk triple exponential smoothing adalah:

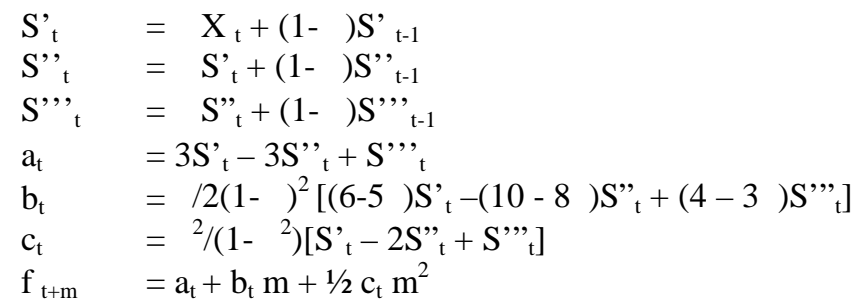

\section{Keterangan :}

$\mathrm{S}_{\mathrm{t}} \quad=$ nilai pemulusan single exponential

S' ${ }^{\prime} \quad=$ nilai pemulusan double exponential

$\mathrm{S}{ }{ }_{\mathrm{t}} \quad=$ nilai pemulusan triple exponential at $=$ nilai rata2 untuk periode $\mathrm{t}$

$\mathrm{b}_{\mathrm{t}} \quad=$ nilai kecenderungan / trend linier

$\mathrm{c}_{\mathrm{t}} \quad=$ nilai kecenderungan $/$ trend parabolik $\mathrm{ft}+\mathrm{m}=$ merupakan nilai peramalan untuk periode

$\mathrm{m} \quad=$ jangka waktu forecast ke depan $(\mathrm{m}=1)$

\section{HASIL DAN PEMBAHASAN}

\subsection{Flowchart Peramalan}

Flowchart peramalan jumlah penumpang Siluet Tour and Travel dengan metode Triple Exponential Smoothingditunjukkan pada Gambar 1. 


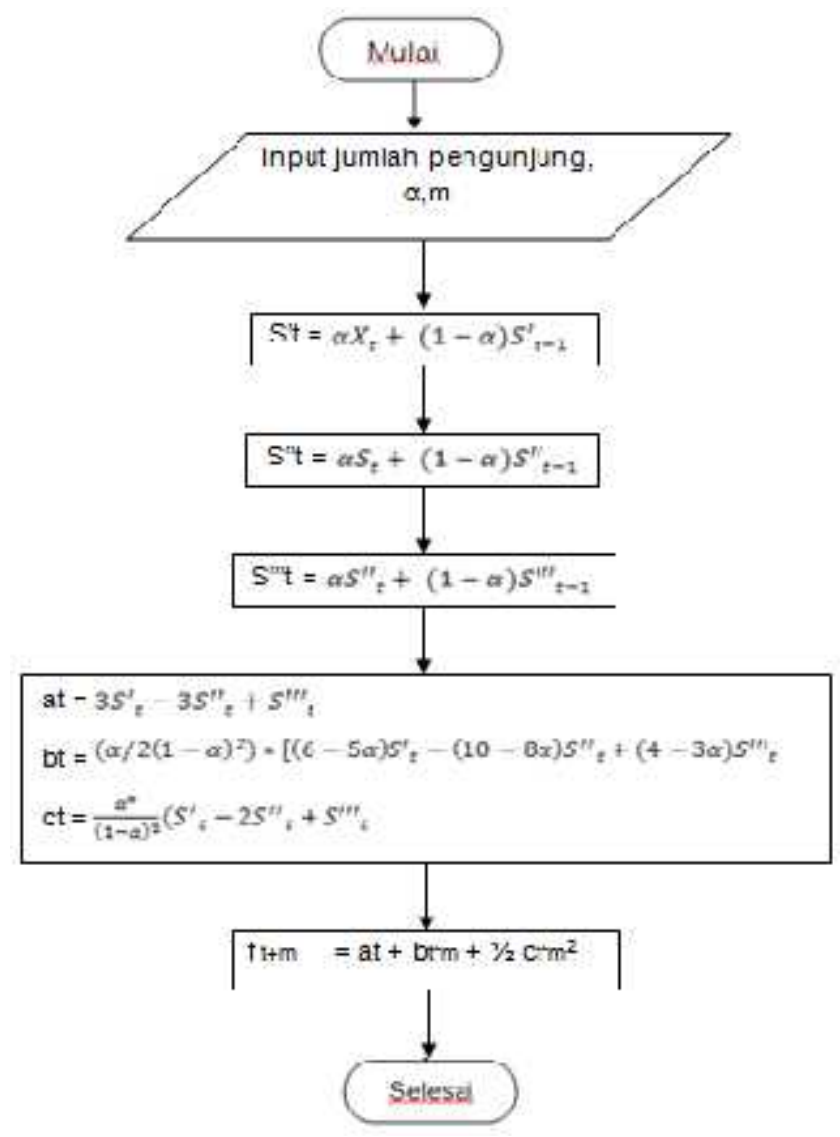

Gambar 1. Flowchart Peramalan

\subsection{Dataset}

Tabel data jumlah penumpang yang telah diakumulasi bisa dilihat pada Tabel 1.

Tabel 1. Data Jumlah Penumpang dan Jumlah Mobil

\begin{tabular}{|c|c|c|}
\hline rebruar. & 119 & 5 Mobl \\
\hline Maret & 120 & 5 Mob1 \\
\hline Apuil & 468 & 6 Mobl \\
\hline Me:t & $i 31 i$ & fi Mab! \\
\hline Jun. & 520 & $6 \mathrm{MOb}$ \\
\hline Jul & 543 & 7 Mub I \\
\hline AQuSt) & 4201 & \& Mobl \\
\hline Septemher & 444 & fi Mab! \\
\hline Qk-9.3er. & 521 & $6 \mathrm{Mobl}$ \\
\hline
\end{tabular}

Dari data tabel dataset dapat dianalisa bahwa jumlah penenumpang Siluet tour and travel kota Malang dari tiap bulan mengalami kenaikan atau penurunan maka dapat disimpulkan bahwa jumlah pengunjung mengalami pasang surut atau tidak stabil sehingga metode yang tepat adalah metode triple exponential smoothing.

\subsection{Proses Perhitungan dengan Triple Exponential Smoothing}

Peramalan dimulai dari periode ke-2 pada data penumpang Siluet tour and travel, $\mathrm{X}_{2}=433$ dan $\mathrm{S}_{1}{ }_{1}=$ 419 menggunakan alpha $=0,1$. Perhitungan single exponential smoothing seperti persamaan berikut : 


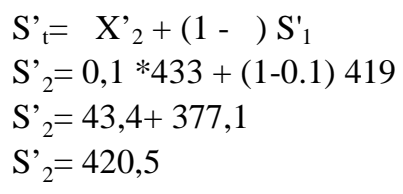

Dari hasil yang diperoleh $\mathrm{S}_{2}=420,5$ maka untuk perhitungan double exponential smoothingnya dengan $\mathrm{S}{ }_{1}=419$ sebagai berikut :

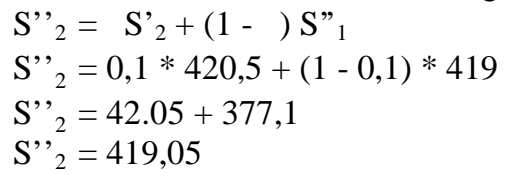

Dari hasil yang diperoleh $\mathrm{S}{ }^{\prime}{ }_{2}=419,05$ maka untuk perhitungan triple exponential smoothingnya dengan $S^{\prime,}{ }_{1}=419$ sebagai berikut :

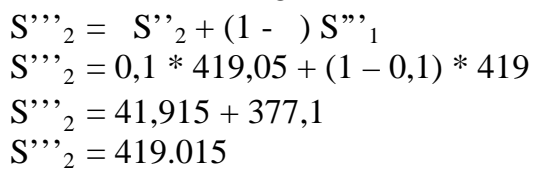

Setelah mendapatkan nilai dari $\mathrm{S}_{1}=420,5, \mathrm{~S}{ }{ }_{1}=419,05, \mathrm{~S}{ }^{\prime}{ }_{1}=419.015$, maka dapat dihitung nilai $a_{t}, b_{t}$, dan $c_{t}$ sebagai berikut:

Perhitungan nilai $\mathrm{a}_{\mathrm{t}}$ :

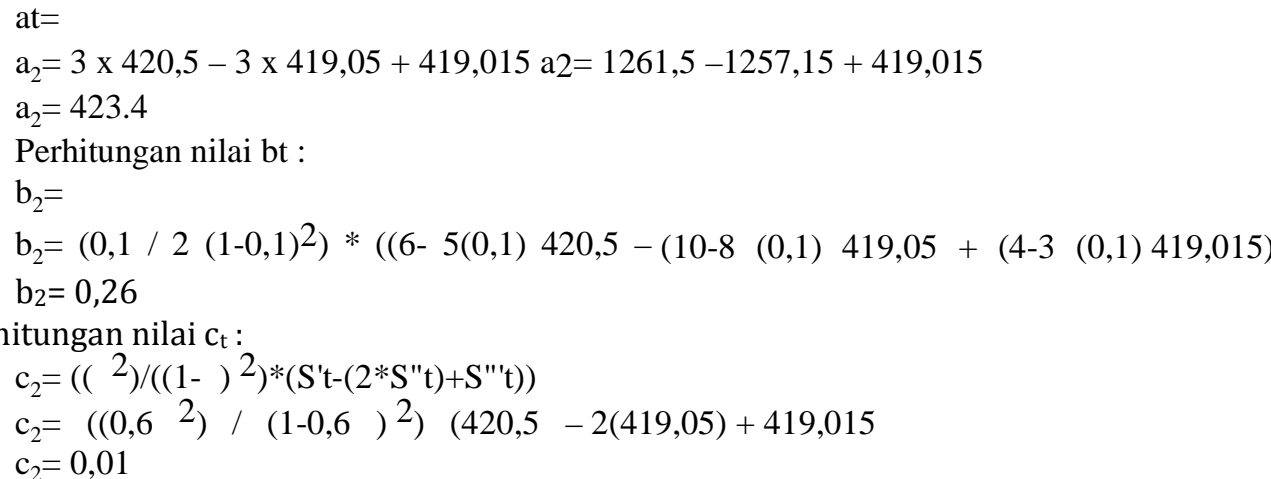

Setelah didapatkan nilai $\mathrm{a}_{2}=423,4, \mathrm{~b}_{2}=0,26$ dan $\mathrm{c}_{2}=0,01$ maka untuk hasil peramalan periode ke- 3 perkiraan adalah :

$\mathrm{f}_{\mathrm{t}+\mathrm{m}}=\mathrm{a}_{\mathrm{t}}+\mathrm{b}_{\mathrm{t}} * \mathrm{~m}+1 / 2 \mathrm{c}_{\mathrm{t}} * \mathrm{~m}^{2}$

$\mathrm{f}_{2+1}=\mathrm{a}_{2}+\mathrm{b}_{2} * 1+0,5\left(\mathrm{c}_{2} * 1^{2}\right)$

$\mathrm{f}_{2+1}=423,665$

\subsection{Presentase Kesalahan}

PE $($ Percentage Error $=(($ Data bulan april - Hasil ramalan bulan april $) /$ Data $\quad$ Bulan april $* 100)=$ $((468-423.06) / 468 * 100)=9.602$

APE (Absolut Percentage Error) $=\mid$ PE bulan april $|=|-20,753 \mid=20,753$

$\mathrm{MPE}=\sum(\mathrm{PE}$ bulan februari 2015 sampai bulan oktober 2015) $/$ Panjang Periode $=25,77 / 7=3,63$

MAPE $=\sum$ (APE bulan februari 2015 sampai bulan oktober 2015 ) $/$ Panjang Periode $=470,442 / 7=12,52$.

Selanjutnya hasil yang didapatkan dari proses peramalan dengan alpha 0,1- 0,9 Beserta PE, APE, MPE dan MAPE bisa dilihat pada Tabel 2. 
Tabel 2. Proses Peramalan dengan alpha 0,1- 0,9 Beserta PE, APE, MPE dan MAPE

\begin{tabular}{|c|c|c|c|c|c|}
\hline Alpha & Ramalan (F) & $\Sigma P E$ & $\sum$ APE & MPE & MAPE \\
\hline 0,1 & 497.75 & 0,258 & 0,876 & 3,63 & 12,52 \\
\hline 0,2 & 499.93 & 0,22 & 0,641 & 0,32 & 12,02 \\
\hline 0,3 & 195.27 & 0,011 & 0,778 & 0,15 & 11,11 \\
\hline 0,4 & 500.80 & 0,063 & $0, i \in$, & 0,90 & 9,166 \\
\hline 0,5 & 513,39 & 0,113 & 0,723 & 1,62 & 10,33 \\
\hline 0,0 & 52780 & 0,140 & 0,734 & 2,09 & 10,22 \\
\hline 0,7 & .54127 & $0,76.3$ & 0,773 & 2,73 & 10,33 \\
\hline 0,8 & 55200 & 0,167 & 0,736 & 2,38 & 10,34 \\
\hline 0,9 & 30160 & 0,131 & $0, i 31$ & 2,23 & 10,23 \\
\hline
\end{tabular}

Dari tabel 2 dapat disimpulkan bahwa tingkat kesalahan terkecil pada data penumpang siluet tour and travel adalah pada alpha 0,4 dengan MPE $=0,9$ dan MAPE $=9,86$ dengan hasil peramalan 500,80.

\subsection{Hasil Implementasi}

Berikut adalah implementasi hasil peramalan jumlah penumpang Siluet Tour and Travel dalam sebuah aplikasi menggunakan software Visual Basic yang bisa dilihat pada Gambar 2.

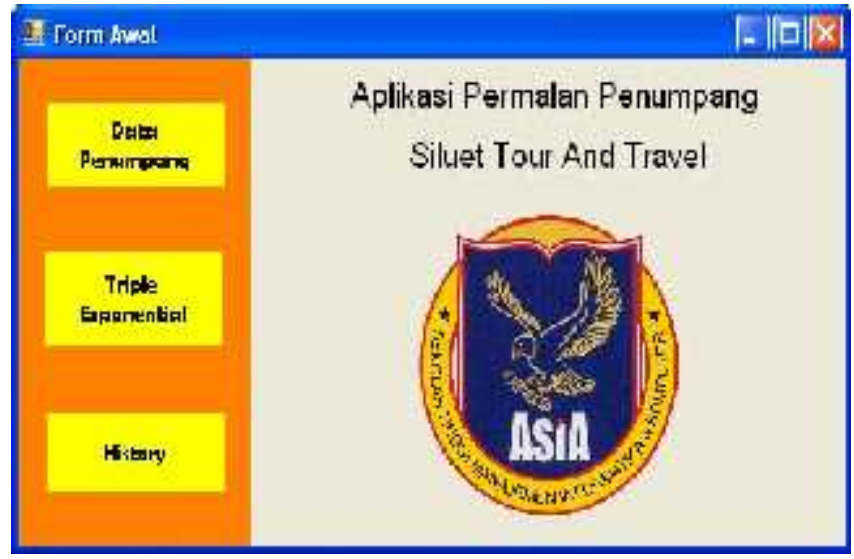

Gambar 2. Tampilan Awal Form Awal

Selanjutnya adalah form data penumpang. Pada form data penumpang digunakan untuk mengolah data penumpang total perhari. Dalam form ini meliputi insert, update, delete, yang ditunjukkan pada Gambar 3.

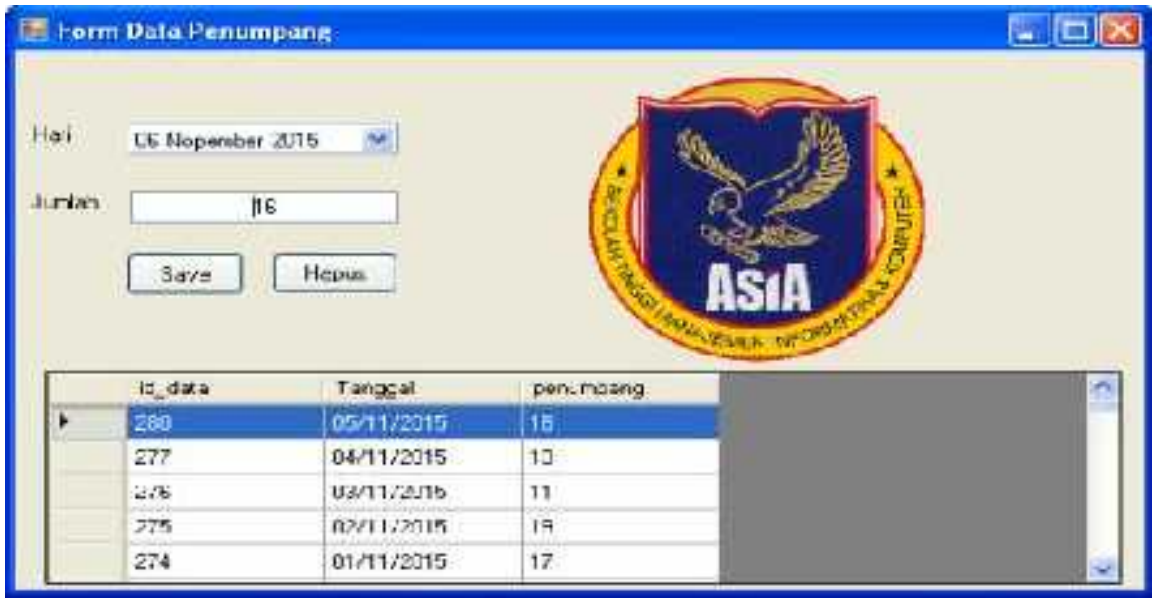

Gambar 3. Form Data Penumpang 
Berikutnya adalah form proses perhitungan menggunakan metode triple exponential menggunakan $\mathrm{m}=1$ digambarkan pada Gambar 4 .



Gambar 4. Form Proses Perhitungan

Setelah itu akan ditampilkan form hasil perhitungan peramalan menggunakan semua alpha. Untuk data terkecil maka akan langsung terblock warna aquamarine. Form hasil peramalan ditunjukkan pada Gambar 5.

\begin{tabular}{|c|c|c|c|}
\hline & Alphe & Isei namalah & MAГL \\
\hline & 0.1 & 497.75 & 12.52 \\
\hline & $11 . ;$ & 4:-4-1, प. & $1 \because 16$ \\
\hline & $n_{.}=$ & $1.97,77$ & 11,11 \\
\hline & 0.1 & 502.06 & 0.00 \\
\hline & $0, t$ & b7 $2,3=$ & $10,3 s$ \\
\hline & $11, \mathrm{~F}$ & $!$ & $11 \% 2$ \\
\hline & n. 7 & IAI . Rr & $\ln .33$ \\
\hline & $0 . \mathrm{C}$ & $552.1 \mathrm{C}$ & 10.24 \\
\hline & $u,=$ & $b b /, b=$ & 10,25 \\
\hline b* & & & \\
\hline
\end{tabular}

\section{KESIMPULAN}

Gambar 5. Form Hasil Peramalan

Dari hasil penelitian dan pembahasan pada bab sebelumnya dapat diambill beberapa kesimpulan yaitu setelah melakukan perhitungan dengan metode Triple exponential Smoothing, maka di dapatkan nilai MAPE terendah yaitu 9,86 dengan $\alpha($ alpha $)=0,4$, sistem dapat memberikan informasi peramalan penumpang siluet tour and travel untuk bulan berikutnya berdasarkan metode Triple Exponential Smoothing, nilai peramalan atau prediksi pada bulan November adalah 500,80 orang, penggunaan metode Triple Exponential Smoothing cukup efektif dalam peramalan yang mengalami data pasang surut dan penggunaan metode Triple Exponential Smoothing cukup mudah untuk diimplementasikan dalam aplikasi peramalan.

\section{DAFTAR PUSTAKA}

[1] Firmansyah, R.2010. Metode Peramalan Exponential Smoothing Pada Jumlah Wisatawan Mancanegara Di Indonesia Dengan Pengemasan R-Package T.E.S.Brown. Universitas Jember.

[2] Makridarkis, dkk.1999. Metode dan Aplikasi Peramalan. Edisi Ke - 2. Jakarta:Erlangga.

[3] Pramitha, W danTanuwijaya H. 2010. Penerapan Metode Exponential Smoothing Winter Dalam Sistem Informasi Pengendalian Persediaan Produk Dan Bahan Baku Sebuah Café. STIKOM Surabaya.

[4] Subagyo, P.1986. Forecasting Konsep dan Aplikasi. Yogyakarta:BPFE. 